\title{
DESOLATION OF STRESS IN WOMEN: CAUSES WHICH TRANSFORM STRESS INTO EXTREMISM AND VIOLENCE
}

\author{
${ }^{1}$ Prof. Dr. Anjum Bano Kazimi, ${ }^{2}$ Ms Amatul Zehra.Kazimi \\ ${ }^{1}$ IQRA University, Karachi,Pakistan Pakistan, E-mail:anjum.bano@iuk.edu.pk \\ 2University of Karachi, Pakistan, E-mail:amatulzehrak@gmail.com
}

\begin{abstract}
According to the medical term, stress is a physical, mental, or emotional factor that causes bodily or mental tension and brings a person to a point of "fight or flight" response, which is a complex reaction of neurologic and endocrinology system. In common terminology, stress is a pressure or a feeling that people have when they are overloaded and struggling to cope with internal or external demands. Resisting or tolerating stress by a person depends on his or her building blocks, those are family, culture, religion, social environment as well as personal strength. Stress bearing power increases with positive support of these factors. But how much a person can absorb, tolerate, and convert stress into positive vibes has certain limits. In eastern culture, it is expected that a girl or woman should exhibit extreme tolerance under every circumstances. These expectations sometimes bring them to a point where their tolerance was exhausted or burst and brought them to a point of violence or terrorism, destruction to herself and to the society. According to Lee K, Lee HK, Kim S.H(2017), people can go to any extreme, they can kill others, or bring destruction to the society, culture, traditions, norms, and morals. How and when do people touch that level especially women? How can these situations be avoided, controlled or modified? How to keep stress under control Is the topic of this research. A qualitative strategy was used to explore how stress is managed, through a deductive method, the data were collected through purposive sampling from the population of five strata of different categories, academics, psychologists, sociologists, criminologists and housewives, to collect in-depth information. From fifteen respondent's data was collected and recorded through unstructured two hours' interview questions, analyses of the responses were done through coding and developing themes. Results reveal that the expectations of the people around, social norms, lack of personal strength, discouragement and taking for granted behavior, lack of communication and fear of losing respect and relationship by women are important factors which bring stress to its height. It is suggested that keeping dependable friends, securing economic independence, developing good communication skills, religious practices, identifying one's own de-stressors, securing and establishing a support network, and prioritizing skills can help in controlling the outburst of stress and any move towards violence and terrorism.
\end{abstract}

Keywords: Stress. violence. terrorism.de- stressors. coping strategies

\section{INTRODUCTION}

Women are more than half of the total population of Pakistan, their participation and contribution to social and economic development is vital. Most countries of the world through sustainable development try to maximize emphases on their health, education and participation in national and global development. Women are the backbone of societal structure and family strength. In eastern culture women are bearing a two-fold burden, they are not only performing family related house hold activities but also supporting family and society through sharing economic burden as earning member whether they live in rural or urban areas.

With the voice raised for equal rights, instead of securing rights demand for responsibility increased for 
women, regardless of whether they are house wives or working women. Researches have highlighted the consequences of these increased demands in the form of stress on women at all places inside or outside of the home at work place and in the society. Lamis DA, Ballard ED, May AM, Dvorak RD (2016). Due to increased socio economic stress and the stressor's level of tolerance among women is declining with the passage of time. Mirza I, Jenkins R (2004). Thus creating numerous problems and resulting in the form of suicidal behavior self-injurious behavior like self-burning, taking drugs, jumping in the wells, rivers or canals. They are not only doing harm to themselves but to the people around them (Khan, M. M., \& Reza, H. 2000), as there are so many cases registered with World Health Organization (2019). in which women killed themselves with three to four small children, after poisoning her husband or other family members or even burning them after killing. It is even reported that daughters killed father or mother which is very un-usual situation and a very drastic change in relationships. It is extremely important to know why women are taking extreme actions, what are the factors that cause these behaviors and what to do to control such bursts of anger, we need to identify those stressors and those factors that make situation so drastic that people lose their senses and cross the threshold of stress to take extreme actions.

\section{METHODOLOGY}

This research is qualitative exploratory in nature. Women above the age of thirty were taken as population through purposive sampling. Three each from five categories. Those who are related to academia, psychology, sociology, criminology or are house wives. Data was collected through open ended interview questionnaire validated through experts opinion from 15 respondents from each category through personal contacts, recording answers to the questions asked. Data was analyzed on Kathy Charmaz-2006, constructivist grounded theory (Morse, J. M \& Stern 2016). All data was initially analyzed for finding similar ideas based on their responses to the questions asked, through initial coding to focused coding and then categorizing responses of the respondents through analytical coding by using constant comparative method and finally extracting themes.

\section{QUESTIONS}

1. People say that now a day's women are taking extreme actions because of stress. What is your opinion about it?

2. Do you know what things/objects/situation/persons make you feel angry or stressed? And why?

3 Have you ever tried to harm/kill yourself? Or others. If yes, why?

4 Why do people take extreme action (like suicide, self-harming, killing others etc.) in their life?

5 How you deal with a stressful situation to keep a situation under control?

6 What are the factors that bring a person to the point of exhaustion?

7 How to avoid or control or modify stress?

\section{REVIEW OF RELATED LITERATURE}

A large number of researches have been done on causes and factors that are responsible for developing suicidal or self-injurious behavior among males and females, researchers also worked on those persons who tried to attempt suicide through different methods. (Bob LewID1, Jenny Huen, 2019). Suicide is a very important and worldwide issue related to health. Because this phenomenon is increasing day by day and is not limited to any specific area, culture or age It is assumed that culture, religion or strong social structure, are the factors that help in stress reduction, but now a day's things are changing so it is very important to find women's perception and commonly used strategies for coping stress and stressful situation as this area of research is not studied with reference to eastern countries specially Pakistan. Halahan and Moose (1987). developed Coping Strategies Scale based on three main areas, cognition, emotion and behavioral method used by the people to overcome their stress. This scale was used by Hamby, Grych,\& Barnyard (2013) after some adaptation. This scale was applied on 497 females through convenient sampling belonging to working women and house wives, result shows that mostly women find emotional or behavioral strategies to deal with stress. Mostly women do not apply cognitive strategies like analyzing situation, thinking critically or logically to present their arguments.

On the bases of Moos scale and Hamby research[---] in the present research ten questions were designed to take data from five different categories or fields: women from education, psychology, sociology, criminology and women who are house wives, to find how they think about and deal with stress; with special reference to Pakistan. It is believed if people use cognitive strategies they can improve a situation and gain control over it. Shirazi, H.R. Ghafarian, (2012) who worked on suicide in Islamic Republic of Iran said that collecting data on 
suicide is very difficult but also said that suicide rate is on the increase especially in the last 25 years and mostly among house wives (54.2\%). Mashreky, S. R. Rahman, F.(2013) who conducted research in Bangladesh, said that suicide kills more than ten thousand people every year in Bangladesh, the rate of suicide is increased and is $17 \%$ higher in rural population and mostly among female between the age of 10 19 years .while majority who committed suicide or attempted suicide were very poor and illiterate Ali, T. S. Mogren, I., \& Krantz, G. (2013) researched on Violence among partners and its impact on Mental Health, the finding showed that violence seriously impact on mental health and psychology of victims.

The Cope Scale (BCS),[----] presenting 14 sub scale each with two items measuring a strategy that one would like to take under some certain kind of stressors. 1. Self-direction 2. Active coping 3. Denial 4. Used instrumental support 5. Positive reframing .6. behavioral disintegration 7. Venting planning 8. Humor 9. Acceptance 10. Religion 11. Self-blame. There are different researches which identified the relationship between education and suicidal behavior, economic stability and suicidal behavior, self-confidence, family support relationship with other family members, personality traits, social status and suicidal behavior. Judi Kidger (2012) worked on prevalence and causes of suicide and self-harming. McGregor (2001) also discussed about the causes of taking extreme actions, in his research Havior says that causes for suicidal behavior or injurious behavior are largely unexplored. Bertalanffy (1938) in Modern Theories of Development has pointed out that accommodating facts without clear theoretical laws can develop crisis for human mind leading to stress. Nock, M. K., Borges, G., Bromet, E. J (2008) explained the importance of early experiences and brain maturation and their relationship with stress. ( Koza, K. L., \& Dant, R. P 2007)studied the effect of interaction and communication as factors for setting the stage for future reactions which can be used as guide line for dealing with stress.

Ayas, T., Deniz, M (2010) found through their research that people use different strategies for coping with stress: adults use non cooperative behavior, and physical violence to deal with stress. Lulofs, R.S \& Cahn, D.D. (2000) discussed conflict theory: their causes and their effect on behavior. Brown, M. Z., Comtois, K. A., \& Linehan, M. M. (2002) studied reasons why people go for suicide. He says that reasons given for suicide attempts are mostly different from reasons for no suicidal self-injury. No suicidal acts are often reported as a way to express anger or to distract oneself while attempted suicides are for making others better off.. Bihari, V., Kesavachandran, C. N., Mathur, (2013) conducted research on relationship between house work load and stress. Leavitt SB (2012) studied health issues as cause of stress. while Berkowitz, A. D., \& Perkins, H. W. (1884) had as their topic, "Stress among Farm Women: Work and Family as Interacting Systems", analysis was made to assess the relative contribution to stress of work-related and family-related variables and to find out whether husband support worked as coping mechanism and work roles may not be as important as interpersonal dynamics, in rural farm families.

Muhammad Saaig and Bushra Ashraf,(2014).conducted research in Islamabad, Pakistan in a Burn Care Centre in which it was concluded that most of the women who attempted suicide were under extreme stress Khan, M. M., \& Reza, H. (2000) says that religious, legal and social, factors make reporting of such incidents taboo and hence their diagnoses. Women were under the age of thirty, there were more single women than married, and "domestic problems" were the most common reason behind suicide. Nock, M. K., Borges, G. (2008). Whose study was about suicide cases from Karachi, KPK, Peshawar, Islamabad, said, that cases varied from city to city and rate of suicide was higher in women than men. Highest was in Larkana, Sindh the World Bank(2006-2018) period suicide rate in Pakistan was approximately 1.4, is 7.28 per 1000 people in 2016.( Baumeister, Roy F. 1990). Suicide is analyzed as a motivational factor to escape from negative self-awareness, and it can be seen as a mean to escape from reality.

Psychological Review, Vol 97(1), Jan 1990, 90-113 carrying research by Baumeister (1990) concluded that suicide is an attempt to escape from self-failures to positive self, or that awareness of self-inadequacies generate negative effect. This deconstructed state brings about stress and irrationality and a person sees suicide as the ultimate step in the effort to escape from a distressing situation. Another researcher concluded that intensity of job stress linked with low social support at work place causes women to consider using avoidance and detachment from the situation, with suicide as the ultimate choice to escape from a problem.

( Kidger, J., Heron, J 2012).conducted research on subjects having age16-17 years who attempted to harm themselves says that inter-relationship between suicidal thoughts, plans and self-injurious behavior is largely unexplored L. Kozaa Rajiv P.Dantb1(2007).concluded that past history of interaction, communication and conflict resolution ability impacts on behavior. (Bridge. JA,2006) said that gender, attributions, resolution strategies, and self-monitoring are important factors to link with behavior. It was shown that males and the persons with high self-monitoring ability, regard their relationships as less intimate, consider themselves as less committed, and use uncooperative and avoidance strategies. When measured on Laudia J. Haferkamp Snyder's Self-Monitoring Scale, while they scored higher in self-monitoring, they saw friendships as less 
intimate and stable, saw their conflicts as more stable, and they used Denial-Avoidant strategies.

(Brown, M. Z., Comtois, K. A., \& Linehan, M. M. 2002). worked on finding reasons behind suicidal and selfinjurious behavior and concluded that reasons for suicidal behavior were different from self-injurious behavior, one suicidal behavior were the reasons of expressing anger, distract oneself or punishing oneself. While reasons for suicide was reported as intended to make others better off (Berkowitz. Alan D. and H. Wesley Perkins (1984) researched on stress related to home tasks and husband support. Research showed that role conflict and husband support have significant relationship with stress. A research study which was conducted in 2008 in three major provinces of Pakistan: Punjab, Sindh and Khyber Pakhtunkhwa tried to calculate the national suicide rates. In Peshawar suicide rates was $0.3 / 100,000$ while in Punjab 2.86/100,000 in Rawalpindi. Rates for men are were higher than women, the highest rates were for men in Larkana, Sindh, province.

\section{DATA ANALYSES}

Data was analyzed on Kathy Charmaz constructivist grounded theory Morse, J. M., Stern (2016) Through initial coding to focused coding and then categorizing responses through analytical coding and constant comparative method converting into specific themes. Seven different themes were identified which are as follow.

\subsection{Situational Factors}

In response to question about the factors that can bring a person to the point of exhaustion or bursting point when he or she is under stress respondent " $A$ " said: In home situation when we feel that other person (partner) is not understanding or accepting our point of view, although it is correct, then this situation causes me extreme stress". Respondent "H" said that her experience was no matter what you do, those who do not want to agree with you, they will not. My husband's behavior of disvaluing my opinion gives me stress. Kessler RC, Berglund P. Borges G, (2005). Respondent "M" said that "interference of non-related persons sometimes makes the situation worse, and increases stress. In the view of respondent "F" when others think and behave as if I am idiot or moron, then I feel stress", Respondents mostly indicated that mistrust of the other persons on you or on your abilities as also mentioned by Teresa Mendonça McIntyre.(2017). Sometimes extra ordinary expectations from you, irregular daily routine in life, irregularity in procedures or promotions in the work place, as well as health issues according to Hawton K, Zahl D(2003)are the very common reasons for developing stress. Ntina Kourmousi (2016). All respondents were agreed on that now a days, economic and social pressures have become stronger stressors. Respondent " $K$ " said that "when there is any stressful situation and people avoid my suggestions and says you know nothing about the world or order me to keep my mouth shut, this make me shout, I do not like being ignored, or people not listening me". Respondent "P" said "when someone blames me or disregards my efforts or my work, that is a strong stressor for me". Nilsson Marie (2017) also identified. Respondent "A" said that "some time children became stressors when they reach the age of adolescence". Respondent "O" said, "stressors change with the passage of time, sometime extended family members are stressors, sometime boss' authority and power are responsible for stress, you know that they are wrong but you cannot say anything ". Mostly all respondents identified financial matters, social responsibilities and political anxiety as well as safety and uncertain future as stressors.

\subsection{Factors that Behave as Catalysts}

Respondents identified those factors which they found could increase or decrease the intensity of stressors. The respondents pointed to many factors, situations, persons or even events that work as catalyst and increase the intensity of stress (Ntina Kourmousi. Evangelos, C. Alexopoulos,(2016). Respondent "E" said "some people behave as if others are slaves and they themselves are the most important persons in the world", Ellen Skinner and Jeffry Beers, (2016) concurred that the presence and words of such persons make the situation more stressful, another respondent said that an uncertain future, tense city situation, changing or alarming situation of economy work as catalysts. At work places, people who are un related interfere, according to (Sharma. Radha, R. and Sir Cary Cooper,2017) and try to give their suggestions or opinions in other's matter which makes the situation more stressful. Sun Ping, Yunxia (2018). One respondent said, "life is getting faster and faster that demands quick and on the spot decisions", those who cannot keep pace with this race find the stress more serious: Isabel Rodríguez (2018).

\subsection{Identifying Extreme or Optimum Point of Stress}

Almost all respondent said that they can identify their critical point of stress, a point they think they cannot tolerate more stress than that. It is a very important factor that shows self-awareness, that can help you in controlling your behavior and also can help you in controlling situation of stress. that also negates the 
concept that women do not react cognitively to a distressing situation. If a person knows about his or her optimum point, then taking a good decision is easier and can be on time to prevent stress from getting unbearable.

\subsection{Self-Coping Strategies}

People apply different strategies to deal with their stress. some try to escape from reality, they do not face the cause of stress, some said that: "women have courage to face the situation and they should". Some said they try to take help from others (Perry, J. C., Fisher, A. L., Caemmerer, J. 2015) discussed such situations and asked respondents about how they coped with such stress.. Respondent "C" said, "I cry, and shout to release my tension, after some time I feel ok. Respondent "A" said, "I not only can control myself but most of the time I mediate to relieve stress among my family and friends, and face the situation. Respondents were in favor of facing the situation or the stress "avoidance is no solution". One respondent, said "I go to sleep when I feel extreme stress, after that I think in a different way". One respondent said I take some medicines to release my tension, otherwise I feel I shall have heart attack ". One said that I always go to my parents' home, talk to them, they always help me in reducing the cause of my stress. (Wang, X. Cai, L. Qian, J. Peng, J. 2014). ", When I feel stress I tell everyone about it and ask them not to bother me anymore, leave me alone ". Another respondent said.: "I do not take stress, I always think the problem is from God" according to Chirico Francesco (2017), "and He will help me, and it happens."

\subsection{Changing Scenario}

Respondent said that time is changing, thought process of women is also changing there is a change in attitude and behavior, although not on larger scale but in urban areas women are reflecting back to social and workplace stressors, raising their voice and showing a little bit resistance against ill treatment and about their rights. Respondent $\mathrm{E}$ said that as literacy is increasing understanding and ability of situation analyses is also increasing which is a good sign, respondent $\mathrm{N}$ and $\mathrm{H}$ said women are reflecting back, saying yes for all odds is declining and media is playing its role in that. Respondent C said, "women should not accept each and every thing, they must resist them". Respondents were in favor of facing the situation of stress boldly as escape is no solution to anything

\subsection{Education as a Solution}

All respondents were in favor of giving education to girls as in their opinion it was the most important factor in developing self-importance and to value one's life. Respondent " $C$ ", "D" and "F" agreed that educated women mostly do not face serious stressors, as people do not take them lightly, Respondents also agreed that now a days taking extreme steps is increasing among women, especially among middle age women( Skinner Ellen and Jeffry Beers, 2016) May be it is social, economic or emotional pressure, but women can improve their own situation as well as that of their family by getting education or at least learning those skills that can help them in getting social or economic stability.( Infurna, F. J., Luthar, S. S. 2016). Women can have a very positive role at homes and at work place if they get awareness about their own strengths and about their rights by having education and social contacts.

\subsection{Causes for Taking Extreme Actions}

When asked about their opinion about why people take extreme actions under stress, they expressed these notions that people want to escape from the situation they do not want to face. It is escape from negative self-feelings, some time to escape from situations and go somewhere where they cannot be answerable to any -one. In some conditions they realize that they have done something wrong and avoid facing consequences. Most of them said that when we feel helpless or have no voice, or seeing people not taking them seriously (Wrosch, C., Miller, G. E. 2009).Being disgraced in front of others, specially the persons they know gives them the feeling of being worthless in others eyes. Respondent "B" said that, "when people do not accept their contribution and work done, they feel disregarded and this gives them a feeling of inadequacy thus making self-awareness painful, they make efforts to escape for self and others". Respondent "P" said that, "when somebody loses position or status either in the family or at work place that gives one a motive to kill oneself or others."

\subsection{Preventive Strategies}

The strategies identified by the respondent's for avoiding extreme stress are:

5.8.1 People do not take educated people lightly. they normally listen to suggestions or arguments if the person is educated, so, to avoid stress, women must have education, it will give them worth. This was also pointed out by Michailidis Evie and Mark Cropley (2017), 
5.8.2 Try to get economic independence. With regard to those women who can bear their own expenses, people mostly do not interfere in their matters, their family gives them importance, this protects them from a number of stressors Those women who are economically independent and earning members of a family are treated differently. They have a voice in matters related to home affairs, or in the family or in society. Researches agreed that value of a person is linked with his or her economic position. If a female is economically strong and having good share in expenditure, people in the family and environment cannot easily neglect her.

5.8.3 It is advised: "Develop a habit of not re-acting immediately. Thinking thrice before taking any action, develop a habit of analyzing a problem and thinking positively. Hold your reactions do not react immediately, it will harm you". (Dashora, P., Erdem, G., Slesnick, N. 2011) advise taking a short break, breath long, change your body position or leave the place, drink a glass of water, collect your arguments then reflect. This time will decrease your stress, will release pressure from your mind, and your brain will start working, towards giving you a good solution

5.8.4 Develop self-awareness, knowing what things, people, situation can be stressor for you, try to avoid them before extreme conditions as Skinner and Jeffry Beers, (2016) have indicated through their research. Identify for yourself, the things you like, the things you do not like, persons or situations you feel are stressors. If you will have prior information about yourself, your emotional intelligence will easily tell you how to deal with alarming situations, peoples, or objects. That will make you alert and you will be ready in advance to face the situation. Practice to improve and use your emotional intelligence.

5.8.5 Develop strong relations in your family, trust them, trust that they will help you overcome problems, help them, you will get help in return. Keep few points in your mind. Never loose contact with your friends from your earlyyears. They can work as filter for your stress, they can give you strength and good feelings to fight with stress or negative situation in your life. Discuss your feelings or problems with them; that will give your negative energy an outlet, that will make you feel better.

5.8.6 Value your life, personality and self. others will value you. Think you are important. Change your attitude toward life. Be sure life never stops for anyone, time will pass without you, all will be settled so why take extreme action? Your life is important for you as a human being so do not do wrong with yourself. Feel your own value and importance. (Chao, R. C.-L. 2011). Take action for yourself, do not make space for others.

5.8.7 Stressful events in our life pile up internally from time to time, when they become too many and un treated even a slight touch can make them fall, a sudden situation which can touch the threshold or cross that limit can make a person to take extreme. Do not pile up your stress, release them after each event, talk about what you feel. If there is no one to listen than write your feelings on a paper it will give an outlet to your tension.

5.8.8 Close family members your husband/wife, children and your parents are always with you, develop a trust among them be a trusted person to them, (Guoliang Yu, Yan Dong, Qi Wang 2016). In return, they will give you trust (Seiffge-Krenke, I., Pakalniskiene, 2011). In difficult times we need trusted persons for help.

5.8.9 Identify for yourself, the things you like, the things you do not like, persons or situations you feel are stressors. If you will have information about yourself, your emotional intelligence will easily tell you about alarming situations, peoples or objects that will make you alert and you will be ready to face the situation in advance. Practice to improve and use your emotional intelligence.

Try to practice developing priority list in each and every situation when you have to take any decision, even if the task is very small. This habit will be helping keeping you away from stressful situations.

\section{CONCLUSION}

As all the respondents were from different strata, it was necessary to analyze their point of view with respect to their specific field of specialization. In response to questions about attempting suicide or extreme action in their life, only one person answered yes, she tried to take her life by taking pills, but three of them said that they reached this point but could not go ahead. (6.6\%). It is clearly indicated by their responses that those who are house wives, identified factors mostly related to relationships (fear of divorce, dishonesty in relationships), living in dire economic conditions and being disvalued. They feel helpless, and release their stress through physical reactions, crying and withdrawal, while psychologists and criminologists indicated almost similar responses, for them strong stressors are environmental situations, interference from others, injustice and high expectations. They reduces their stress mostly through resistance ,argument, and, in extreme conditions withdrawal. Sociologists expressed concern about social relationships and expectations as main cause of stress. They emphasized education, family and social support as solutions for stress. For 
educationists, lack of communication, blame games and disrespect of opinion are stressors. They release their stress through delayed technique and fight for rights. The common factors among all was that they all thought that educating women is a solution of coping with stress. They all can identify their optimum point of stress. Remaining under optimum stress situation can lead to dangerous explosion or an extreme step, so they need psychological therapy to control themselves from dangerous situation as they feel they are at that level.

This research was a small scale research which was focused on women only, as women take responsibility of developing the home, society and the world. Results clearly indicated that women can analyze the situations, they know about their own psyches and those factors that are, or can be stressors for them. They clearly identified the reasons behind taking extreme actions in life and also identified solutions for them. The main focus points were, feeling importance of education, economical independence, value as a person and having their point of view heard as the solution to stress

\section{REFERENCE LIST}

Ayas, T., Deniz, M., Kağan, M., \& Kenç, M. F. (2010). "An investigation of Conflict Resolution Strategies of Adolescents." Procedia-social and Behavioral Sciences, 2(2), 3545-3551.

Ali, T. S., Mogren, I., \& Krantz, G. (2013). "Intimate partner violence and mental health effects: A populationbased study among married women in Karachi", Pakistan. International Journal of Behavioral Medicine, 20(1), 131-139.

Berkowitz, A. D., \& Perkins, H. W. (1984). Stress among farm women: Work and family as interacting systems. Journal of Marriage and the Family, 161-166.

Brown, M. Z., Comtois, K. A., \& Linehan, M. M. (2002). "Reasons for suicide attempts and non-suicidal selfinjury in women with borderline personality disorder". Journal of Abnormal Psychology, 111(1), 198.

Baumeister, R. F. (1990). "Suicide as escape from self", Psychological Review, 97(1), 90.

Bihari, V., Kesavachandran, C. N., Mathur, N., Pangtey, B. S., Kamal, R., Pathak, M. K., \& Srivastava, A. K. (2013). "Mathematically derived body volume and risk of musculoskeletal pain among housewives in North India". PloS one, 8(11), e80133.

Bertalanffy, L. V., \& Woodger, J. H. (1938). Modern Theories of Development.

Bridge JA, Goldstein TR, Brent DA." Adolescent suicide and suicidal behavior." J Child Psychology: Psychiatry. 2006; 47(3-4): 372-394. https://doi.org/10.1111/j.1469-7610.2006.01615.x PMID: 16492264

Chirico, F. (2017). "Religious belief and mental health in lay and consecrated Italian teachers." Journal of Religion and Health, 56(3), 839-851.

Chao, R. C.-L. (2011). "Managing stress and maintaining well-being: Social support, problem-focused coping, and avoidant coping". Journal of Counseling \& Development, 89, 338-348.

Dashora, P., Erdem, G., Slesnick, N. (2011). "Better to bend than to break: Coping strategies utilized by substance abusing homeless youth". Journal of Health Psychology, 16, 158-168. doi:10.1177/1359105310378385

Guoliang Yu, Yan Dong, Qi Wang and Ran an (2016), "Reducing teacher stress: improving humanized management of Chinese teachers", Journal of Chinese Human Resources Management, 7, 2, (82),

Hamby, S., Grych, J., \& Banyard, V. L. (2013). “Life paths measurement packet'. Sewanee, TN: Life Paths Research Program.

Hawton K, Hall S, Simkin S, Bale E, Bond A. (2003) Deliberate self-harm in adolescents: a study of characteristics and trends in Oxford, 1990-2000. J Child Psychol Psychiatry. 44 (8): 1191-1198. 10.1111/1469-7610.00200.

Isabel Rodríguez, Malgorzata Wanda Kozusznik, José María Peiró and Núria Tordera, "Individual, co-active and collective coping and organizational stress: A longitudinal study", European Management Journal, 10.1016/j.emj.2018.06.002, (2018). 
Kourmousi, N., \& Alexopoulos, E. C. (2016). "Stress sources and manifestations in a nationwide sample of pre-primary, primary, and secondary educators in Greece". Frontiers in Public Health, 4, 73.

Khan, M. M., \& Reza, H. (2000). "The pattern of suicide in Pakistan" Crisis: The Journal of Crisis Intervention and Suicide Prevention, 21(1), 31.

Koza, K. L., \& Dant, R. P. (2007). "Effects of Relationship, Climate, Control mechanism, and Communications on conflict resolution behavior and performance outcomes". Journal of Retailing, 83(3), 279-296.

Kidger, J., Heron, J., Lewis, G., Evans, J., \& Gunnell, D. (2012). "Adolescent self-harm and suicidal thoughts in the ALSPAC cohort: a self-report survey in England". BMC Psychiatry, 12(1), 69.

Lee, K., Lee, H. K., \& Kim, S. H. (2017). "Temperament and character profile of college students who have suicidal ideas or have attempted suicide." Journal of Affective Disorders, 221, 198-204

Lamis, D. A., Ballard, E. D., May, A. M., \& Dvorak, R. D. (2016). "Depressive symptoms and suicidal ideation in college students: the mediating and moderating roles of hopelessness, alcohol problems, and social support." Journal of Clinical Psychology, 72(9), 919-932.

Leavitt, S. B. (2013). Soaring Burden of Musculoskeletal Pain

Lulofs, R.S \& Cahn, D.D. (2000) Conflict from Theory to Action (2nd Edition). Boston: Allyn and Bacon

McIntyre, T. M., McIntyre, S. E., Barr, C. D., Francis, D. J., \& Durand, A. C. (2017). Towards a Dynamic x Integrative Theory of Educator Stress. In Educator Stress (pp. 261-289). Springer, Cham.

McGregor, I., Zanna, M. P., Holmes, J. G., \& Spencer, S. J. (2001). Compensatory conviction in the face of personal uncertainty: going to extremes and being oneself. Journal of Personality and Social Psychology, 80(3), 472.

M. M., \& Reza, H. (2000). The pattern of suicide in Pakistan. Crisis: The Journal of Crisis Intervention and Suicide Prevention, 21(1), 31. Prevention and Suicide Prevention, 21(1), 31.

Mirza, I., \& Jenkins, R. (2004). Risk factors, prevalence, and treatment of anxiety and depressive disorders in Pakistan: systematic review. BMJ, 328(7443), 794.

Mashreky, S. R., Rahman, F., \& Rahman, A. (2013). Suicide kills more than 10,000 people every year in Bangladesh. Archives of Suicide Research, 17(4), 387-396.

Michailidis, E., \& Cropley, M. (2017). Exploring predictors and consequences of embitterment in the workplace. Ergonomics, 60(9), 1197-1206.

Morse, J. M., Stern, P. N., Corbin, J., Bowers, B., Charmaz, K., \& Clarke, A. E. (2016). Developing Grounded Theory: The Second Generation. Routledge.

Nock, M. K., Borges, G., Bromet, E. J., Cha, C. B., Kessler, R. C., \& Lee, S. (2008). Suicide and suicidal behavior. Epidemiologic Reviews, 30(1), 133-154.

Ntina Kourmousi and Evangelos C. Alexopoulos,(2016) Stress Sources and Manifestations in a Nationwide Sample of Pre-Primary, Primary, and Secondary Educators in Greece, Frontiers in Public Health, 4,

Nilsson, M., Blomqvist, K., \& Andersson, I. (2017). Salutogenic resources in relation to teachers' work-life balance. Work, 56(4), 591-602.

Nock, M. K., Borges, G., Bromet, E. J., Cha, C. B., Kessler, R. C., \& Lee, S. (2008). Suicide and suicidal behavior. Epidemiologic Reviews, 30(1), 133-154

. Perry, J. C., Fisher, A. L., Caemmerer, J. M., Keith, T. Z., Poklar, A. E. (2015). The role of social support and coping skills in promoting self-regulated learning among urban youth. Youth \& Society, 1-20. doi: $10.1177 / 0044118 \times 151618313$

Skinner, E., \& Beers, J. (2016). Mindfulness and teachers' coping in the classroom: A developmental model of teacher stress, coping, and everyday resilience. In Handbook of mindfulness in education (pp. 99118). Springer, New York, NY

Sun, P., Qu, Y., Wu, J., Yu, J., Liu, W., \& Zhao, H. (2018). Improving Chinese Teachers' Stress Coping Ability through Group Sandplay. The Spanish Journal of Psychology, 21.

Sharma, R. R., \& Cooper, S. C. (2017). Prelims', Executive Burnout. 
Saaiq, M., \& Ashraf, B. (2014). Epidemiology and outcome of self-inflicted burns at Pakistan Institute of Medical Sciences, Islamabad. World Journal of Plastic Surgery, 3(2), 107.

Shirazi, H. R., Hosseini, M., Zoladl, M., Malekzadeh, M., Momeninejad, M., Noorian, K., \& Mansorian, M. A. (2012). Suicide in the Islamic Republic of Iran: an integrated analysis from 1981 to 2007

Spirito, A., \& Esposito-Smythers, C. (2006). Attempted and completed suicide in adolescence. Annual Review of Clinical Psychology, 2, 237-266.

Teresa Mendonça McIntyre, Scott E. McIntyre, Christopher D. Barr, David J. Francis and Angelia C. Durand,(2017). "Towards a Dynamic Integrative Theory of Educator Stress", Educator Stress, 10.1007/978-3-319-53053-6_12, (261-289),

Wang, X., Cai, L., Qian, J., Peng, J. (2014). "Social support moderates stress effects on depression". International Journal of Mental Health Systems, 8, 41. doi:10.1186/1752-4458-8-41.

World Health Organization. Suicide data. World Health Organization. 2019; Available from: htt.

ps doi:10.1037/a0015172://www.who.int/mental_health/prevention/suicide/suicideprevent/en/

Wrosch, C., Miller, G. E. (2009). Depressive symptoms can be useful: Self-regulatory and emotional benefits of dysphoric mood in adolescence. Journal of Personality and Social Psychology, 96, 1181-1190.

Yu, G., Dong, Y., Wang, Q., \& An, R. (2016). Reducing teacher stress: improving humanized management of Chinese teachers. Journal of Chinese Human Resource Management, 7(2), 82-99 